\title{
The Interplay between Social Capital and Knowledge Contribution in Online User Communities
}

Jie (Kevin) Yan

Wright School of Business

Dalton State College

Georgia, USA

Email: jyan@daltonstate.edu

\section{Dorothy Leidner}

Hankamer School of Business

Baylor University and Lund University

Texas, USA

Email: Dorothy_Leidner@baylor.edu

\section{Hind Benbya}

Montpellier Business School

Montpellier, France

Email: h.benbya@montpellier-bs.com

\section{Weifei Zou}

Fox School of Business

Temple University

Pennsylvania, USA

Email: weifei.zou@temple.edu

\section{Abstract}

Firms have been increasingly relying on online user communities (OUC) to access external, distant knowledge and expertise. Previous research on OUC has largely investigated the influence of individuals' social capital on their knowledge sharing behavior. In this study, we propose a spiral view on the relationship between social capital and knowledge contribution. We suggest that there are two-way interactions between individuals' social capital and their knowledge contribution in online user communities. To test our proposition, we collected and analysed participation data of 3,512 users from the OUC of BMC, a global leader in innovative software solutions. We discuss the theoretical and practical implications of our study for the online user community literature as well as the broader context of online community.

Keywords: Social capital, Knowledge contribution, Online user communities, Two-way relationship, Granger causality 


\section{Introduction}

Firms have been increasingly relying on online user communities (hereinafter OUC) to access external, distant knowledge and expertise (Jeppesen and Frederiksen 2006; Yan et al. 2018). Participants or members in OUC are mainly product users of the host firm. They voluntarily engage in the community and contribute their knowledge and expertise about existing product support and new product development. Much research has focused on understanding why users are willing to cooperate with host firms and contribute their knowledge to the community (e.g., Porter and Donthu 2008; Jeppesen and Frederiksen 2006). An emergent line of inquiry has emphasized the social capital aspect of community engagement (e.g., Wasko and Faraj 2005). Social capital refers to the collective resources emerging from and embedded inside a social network, as a result of the interconnected relationships of its members (Nahapiet and Ghoshal 1998). Prior studies on social capital in OUC suggested that participants are embedded in the social structure of their community and that social capital building goals plays a major role in their knowledge contribution behavior.

Existing empirical IS research have revealed significant effects of social capital on knowledge contribution in OUC (e.g., Robert et al. 2008; Nov et al. 2012) but has primarily emphasized and theorized a linear relationship between social capital and knowledge contribution. Such a relationship falls short of revealing the dynamic interplay or co-evolution between social capital and knowledge contribution that might explain why the social capital emerged in the first place or how it can be sustained over time. Thus, the goal of this study is to contribute to a better understanding of the interplay between social capital and knowledge contribution in OUC. We investigate the interactions between users' knowledge contribution, including both the quantity and the quality dimensions, and their social capital, including the structural, cognitive, and relational dimensions. Through a multidimensional, dynamic analysis of knowledge contribution and social capital, we seek to provide a robust and complete picture of the interplay between social capital and knowledge contribution. More specifically, we ask the following research questions: 1) is there a one-way or two-way relationship between social capital and knowledge contribution, and 2) does the causal relationship apply to users with different participation levels?

Investigating the above questions has several theoretical implications. First, existing theories on social network have proposed a two-way, dynamic relationship between structural social capital and knowledge contribution in both online and offline settings (see Wasko et al. 2004; Perry-Smith and Shalley 2003). However, to the best of our knowledge, no published studies have empirically investigated such a relationship. Our study therefore takes the first step towards this direction by empirically examining a two-way relationship between social capital and knowledge contribution. Further, we extend current research by investigating the three dimensions of social capital (structural, cognitive and relational) simultaneously. This is important in order to distinguish the impact each dimension has in the presence of the other two. From a broader online community perspective, the findings of our study should be applied not only to the OUC context but also to other forms of online communities. This includes Q\&A, open source and various open innovation communities where the dynamics of knowledge creation and exchange determine the long-term success of communities (Benbya 2016; Faraj et al. 2011).

Second, our study holds implications for other research streams in the online community literature. For instance, online community leadership as an emerging research stream focuses on the formation of leadership and the role of leaders in online communities (Johnson et al. 2017). It has been found that knowledge contribution and social capital of individuals are two key antecedents of leadership in online communities (Faraj et al. 2015). Members, for example, with a central network position who contribute frequently are more likely to be identified as leaders. Our study suggests that the path to leadership in OUC may entail ongoing interactions between individuals' knowledge contribution and social capital. As one changes, so does the other. In other words, while both knowledge contribution and social capital affect leadership independently, it is essential to account for the reciprocity between knowledge contribution and social capital and examine how such dynamics determine the emergence of leadership in online communities.

Moreover, our findings may help explain how social capital initially emerges from knowledge contribution in some online marketplaces (e.g., Amazon reviews) and how social capital translates into other capital forms (e.g., game credits) as a result of participation in online games. Answers to these questions are still unclear to date (Faraj et al. 2011). Overall, the present paper holds the potential to not merely consolidate extant OUC literature but provide extensions by examining a two-way relationship between social capital and knowledge contribution. Our findings would also add a layer of explanation to the participation and contribution dynamics in many other types of online communities. 


\section{The Interplay between Social Capital and Knowledge Contribution}

A large body of extant OUC research has investigated the relationship between knowledge contribution and social capital. Studies in this research stream, however, have largely focused on examining the effects of users' social capital on their knowledge contribution. Social capital is typically defined as "resources embedded in a social structure that are accessed and/or mobilized in purposive action" (Lin 2001, p.29). Drawing upon the seminal work of Nahapiet and Ghoshal (1998), this research stream typically conceptualizes social capital as consisting of three distinct dimensions: structural, cognitive, and relational (e.g., Wasko and Faraj 2005).

Structural capital refers to the connections and structural links among individuals (Nahapiet and Ghoshal, 1998). Research on the structural aspect of social capital has tended to focus on the structural position of individuals and how it impacts knowledge exchange in OUC (Huysman and Wulf 2006). Whelan (2007), for example, finds that community members' core/periphery structure and connectivity influence their knowledge contribution. Dahlander and Frederiksen (2012)'s research shows that users' position in the core/periphery structure of an OUC is consequential for knowledge contribution. Cognitive capital refers to the capability of individuals to understand and apply knowledge when connecting with each other (Nahapiet and Ghoshal 1998). Research on the cognitive aspect of social capital has largely focused on the cognitive benefits users anticipate from engaging in OUC (Huysman and Wulf 2006). For instance, Nambisan and Baron's research reveals that users' expectations of expertise enhancement and actual experiences in community learning are significantly related to users' participation in value creation and innovation (Nambisan and Baron 2010). Finally, relational capital refers to the characteristics of the relationship such as mutual respect, trust and generalized reciprocity (Nahapiet and Ghoshal 1998). Several studies on OUC have found that community trust (or the norm of collaboration) affects users' knowledge-sharing intentions with both other users and the host firm (e.g., Porter and Donthu 2008; Wasko et al. 2004). And building a norm of reciprocity has significant effects on the quality and quantity of knowledge contribution (e.g., Dholakia et al. 2004).

The discussion above reveals significant effects of social capital on knowledge contribution in OUC. However, the relationship between knowledge contribution and social capital can be relevantly examined in both directions. It is intuitive to expect that an individual's knowledge contribution should, in turn, influence his/her social capital in the community. For example, for users who extensively participate in product support and contribute their knowledge, they receive more connections or ties and thereby gain reputational benefits and community status (Phang et al. 2009). This changes their structural capital in the community. Therefore, while studies relying on social network and collective action theories have shown that network outcomes are affected by network structures (Burt 2004; Nahapiet and Ghoshal 1998), a largely ignored dimension is how network outcomes (e.g., knowledge exchange) will in turn change network structures.

Further, users should also develop their expertise and skills by contributing knowledge in the community. As a user contributes his/her own knowledge, the user is involved in the knowledge exchange process, either actively or passively. The user may, for example, discuss his/her answers with others, read and comment on answers of others or simply receive a notification of the marking of a best answer. In other words, we suggest that in OUC, knowledge contribution itself motivates the contributor to interact with others who share the same practice and thereby learn the knowledge, skills and norms of the practice over time. This developed expertise or cognitive capital then drives the user to continue to share his/her knowledge in the community. Unlike previous studies largely assuming knowledge contribution depends on pre-determined cognitive capital (e.g., Wasko and Faraj 2005), our study seeks to examine cognitive capital as a key outcome of knowledge contribution.

Finally, the norm of collaboration and trust should be cultivated between users who reactively and proactively contribute their knowledge in the community. As users receive incoming ties and derive expertise and skills resulting from their knowledge contribution, they are willing to develop trust and a sense of reciprocity with others (Dholakia et al. 2004). A strong norm of reciprocity and trustworthiness in the collective will, in turn, reward individual efforts and ensure continual contributions (Dholakia et al. 2004). These combined should impact relational capital between users in the community. Overall, we suggest that understanding the interplay between knowledge contribution and social capital is of great importance for scholars to advance theories and for practitioners to build a thriving community but remains under-investigated. 


\section{Methodology}

\subsection{Data}

We collected our data from the OUC of BMC, a global leader in innovative software solutions headquartered in Houston, Texas. BMC established its OUC in 2002 for product support and new product development and has since developed a successful, long-term relationship with its product users. As of January 2016, the community has 26,597 registered members. To create a sample of users for the study, we utilized the community's member list which ranks all members based on their community levels (i.e., points earned based on cumulative contributions) and selected a stratified random sample of 6,836 users. Doing so allows us to ensure that the dataset represents various population members. We then checked the record of recent community activities of each user in our dataset and removed those users who did not have any community activities during the last 3 months. Members who do not have any login records during the past 3 months were assigned with a status of "inactive" by the system. The entire process results in a total of 3,512 users included in our dataset.

We collected the users' participation data from their online community profiles. Community profiles include each user's demographic data (e.g., name, company and title), network data (following/followers), contribution data (e.g., answers and ideas), reputation data (e.g., points and levels), etc. Through the profile menus such as "Content", "Connections" and "Reputation", users can access more detailed information such as the discussions and threads they have participated in, the profiles of people following them, and the entire ranking list of the community. Figure 1 provides an example of an online community profile.

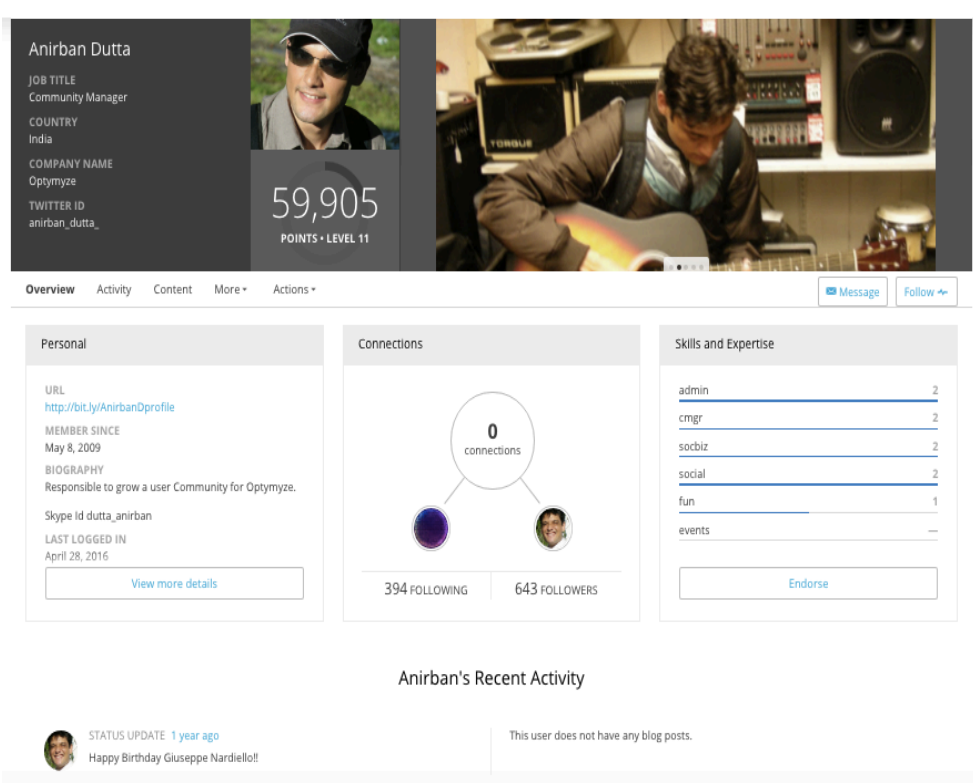

Figure 1. An Example of Online Profile

\subsection{Variables and Measures}

To examine the dynamics between social capital and knowledge contribution, we focus on three groups of variables. They are: 1) users' initial social capital including structural, cognitive, and relational, 2) users' knowledge contribution including both the quantity and quality dimension, and 3) the changes of users' structural, cognitive and relational capital. We seek to investigate whether the initial social capital will predict users' knowledge contribution, which will, in turn, determine the change in users' social capital. We measured all the variables via each user's online community profile on a weekly basis from March $6^{\text {th }} 2016$ to July $30^{\text {th }} 2016$, a total of 21 weeks.

To measure the initial structural capital each user possesses at the beginning of our research period, we utilized the total number of followers a user has in the community. The more followers a user has, the more closely the user moves toward the core structure of an online community (Borgatti 2005). To measure the initial cognitive capital level of each user, we recorded and coded all the helpful and correct answers a user had contributed before March 2016. We coded the answers as follows: an answer would receive 3 points if it was marked as "correct", 2 points if marked as "helpful", and 1 point if not marked. 
We then summed up the points for each user and used this cumulative score to represent the initial cognitive experience (knowledge and expertise) a user had at the beginning of our research period. We measured initial cognitive capital in this way considering that individuals' level of knowledge and expertise is associated with their knowledge contribution in the community (Wasko and Faraj 2005). Drawing upon previous studies (Borgatti and Cross 2003), the initial relational capital was measured by counting the number of ties where two users followed each other. For example, if a user had 5 connections where the user and the other user followed each other, the user would receive a relational score of 5 . Research on social media indicates that when individuals choose to follow each other, they tend to trust each other to an extent and are willing to interact for reciprocity (Coleman 1988).

The variables of knowledge contribution (i.e., quantity and quality) were measured at the end of each week (i.e., the beginning of the next week). We measured knowledge contribution using each user's participation data during the current week. Specifically, we again categorized each user's discussion contributions into correct answers, helpful answers and others. A user would receive 3 points if one of his/her answers was marked as correct, and 2 points if marked as helpful, and 1 point if it received no marks. We then summed up all the points to measure the quantity dimension of the user's knowledge contribution; the quality dimension was measured by only counting the points of correct and helpful answers.

The variables of the changes of structural, cognitive and relational capital were also measured at the end of each week using each user's participation data. For the change of cognitive capital, we measured it by identifying whether the correct and/or the helpful answers in the discussions a user participated were contributed by the user or others. We suggest that the user should, to some extent, learn from peers' correct and/or helpful answers if such answers appear in the discussion threads ${ }^{1}$, which should result in change of cognitive capital. To quantify the cognitive change, we used the cumulative score of correct answers (3 points/each) and helpful answers ( 2 points/each) contributed by others to reflect the user's change of cognitive capital in the current week.

The change of structural capital was measured by recording the number of new followers of each user at the end of each week. However, whether the new followers resulted from a user's knowledge contribution is unobservable. To overcome this issue, we checked each new follower's online profile to determine whether the follower and the focal user had participated in the same discussion threads. We suggest that the following action should, to some extent, result from the knowledge contribution if the two users had participated in the same discussions. Based on this criterion, we were able to remove those new followers whose motives were "unidentifiable". We then recorded the number of new ties where the focal user and the new follower followed each other as the change of relational capital.

\subsection{Modelling and Estimation Approach}

In this study we are interested in 1) whether there is a one-way or two-way relationship between social capital and knowledge contribution, and 2) whether the relationship is applicable to users with different levels of participation. To examine the first question, we employed the Granger causality test (Granger 1969). The Granger test for causality considers the following questions: is it social capital that leads to knowledge contribution or is it knowledge contribution that causes changes of social capital, or does both causal relationships exist?

The Granger causality test of two variables is commonly conducted by regressing one variable on its own lagged values and on lagged values of the other variable (Greene 2011; Heshmati and Löö 2008). One variable is explained to Granger cause the other variable if the past values of both variables are useful in predicting the dependent variable (Greene 2011). Given this, we used the following models to examine the Granger causal relationship between social capital (y), social capital change ( $\Delta \mathrm{y})$ and knowledge contribution (x):

$$
\begin{aligned}
& \Delta y_{\mathrm{it}}=\alpha_{\mathrm{ot}}+\sum_{\mathrm{l}=1}^{\mathrm{n}} \alpha_{\mathrm{lt}} \Delta \mathrm{y}_{\mathrm{i}, \mathrm{t}-\mathrm{l}}+\sum_{\mathrm{l}=1}^{\mathrm{n}} \beta_{\mathrm{lt} \mathrm{Xi}, \mathrm{t}-\mathrm{l}}+\varepsilon_{\mathrm{it}} \\
& x_{\mathrm{it}}=\gamma_{\mathrm{ot}}+\sum_{\mathrm{l}=1}^{\mathrm{n}} \gamma_{\mathrm{lt}} \mathrm{X}_{\mathrm{i}, \mathrm{t}-\mathrm{l}}+\sum_{\mathrm{l}=1}^{\mathrm{n}} \delta_{\mathrm{lt}} \mathrm{y}_{\mathrm{i}, \mathrm{t}-\mathrm{l}}+\varepsilon_{\mathrm{it}}
\end{aligned}
$$

where $t$ is the time period (i.e., 21 weeks from March to August), $i$ is the number of observations (i.e., 3,512 users) in each week, and $\mathrm{n}$ is the number of lags selected. Notably, the error term ( $\varepsilon$ ) follows a two-

\footnotetext{
1 Having participated (e.g., comments or replies) in a discussion, a user will receive a message (via email and on community app) if a helpful or a correct answer is marked by the asker.
} 
way error component structure (Baltagi 2001). It consists of an unobservable user specific $(\lambda)$, time specific $(\mu)$ and a random error term $(\tau)$, i.e., $\varepsilon_{\mathrm{it}}=\lambda_{\mathrm{it}}+\mu_{\mathrm{it}}+\tau_{\mathrm{it}}$.

In terms of the choice of the number of lags, overall, using large lags helps rule out autocorrelation while small lags increase degrees of freedom (Greene 2011; Heshmati and Lööf 2008). Our selection of number of lags is empirical rather than theoretical. Specifically, for each causality test, we added one lag at a time and compare the statistics based on the Schwarz information criterion (SIC), considering that our sample size is large (Cavanaugh and Neath 1999). We then used the results from this procedure to determine the appropriate lag length for the causality tests. We suggest that the causal effect is transitory if it holds only for a few lags and is persistent if the effect holds for multiple, consecutive lags (Greene 2011; Heshmati and Lööf 2008).

Our second question concerns whether the causal relationships hold true for users with different levels of participation. To this end, we categorized users into different participation levels based on their community levels. Given that the community level depends upon users' earned ${ }^{2}$ points in the community, it reflects how active a user has participated in the community. We divided all the 3,512 users into two groups with low and medium participation levels and high participation level, respectively. We chose Level 9 (there are a total of 13 levels based on community points earned) as the cut-off level considering that according to the community's reputation system, Levels 9 13 represent highly experienced users with a status of "Expert", "Master", "Guru”, "Grand Master" and "Emperor", respectively. Consequently, there are 3,330 users (Levels 1 8) in the low and medium group and 182 users (Levels 9 13) in the high group.

Given the above, our empirical study employs two strongly balanced panel models spanning 21 weeks. One panel includes 3,330 users (Panel 1) and the other panel has 182 users (Panel 2). We constructed both panels based on user-week pairs, resulting in 69,930 observations in Panel 1 and 3,822 observations in Panel 2. For each user-week pair, variables examined include social capital (i.e., the initial social capital level at the beginning of week $t$ ), knowledge contribution during week $t$, and the change of social capital during week $\mathrm{t}$ (which, in turn, determines the initial social capital level at the beginning of week ( $t+1)$ ). Then each Granger causality test between two variables was conducted using vector auto regressive (VAR) with the within estimation method. The use of fixed-effects method allows us to account for unobservable user and time specific effects in the error term (Greene 2011).

\subsection{Results}

Tables 1 presents the descriptive statistic and correlations of our panel data. The averages are relatively low in Panel 1 because of excess zeros in the observations. The correlation between the quality and quantity of knowledge contribution is high (i.e., o.67) in Panel 2, indicating that users with higher participation levels may be more likely to contribute helpful and correct answers. Tables 1 and 2 in the Appendix illustrate the results of the lag order selection for each pair of variables. Given the time period of 21 weeks in each panel, we were able to include one lag at a time and run the procedure up to 20 lags. The SIC criterion, as noted earlier, was employed and the corresponding results in the tables suggest using lag structures including 1-lag, 2-lag, 7-lag and 8-lag. We chose the 2-lag structure for the best balance of efficiency and accuracy as well as for the consistency in reporting the results of causality tests.

\begin{tabular}{|c|c|c|c|c|c|c|c|c|c|c|c|c|}
\hline \multicolumn{13}{|c|}{ Low and Medium Participation Levels (Panel 1: 3,330 users; 69,930 observations) } \\
\hline Variable & Mean & S.D. & Min & Max & 1 & 2 & 3 & 4 & 5 & 6 & 7 & 8 \\
\hline SC & 1.06 & 1.93 & O & 23 & 1.00 & & & & & & & \\
\hline $\mathrm{CC}$ & 3.94 & 5.83 & O & 68 & 0.24 & 1.00 & & & & & & \\
\hline $\mathrm{RC}$ & 0.74 & 1.50 & $\mathrm{O}$ & 26 & 0.36 & 0.21 & 1.00 & & & & & \\
\hline$\Delta S C$ & 0.43 & 1.04 & -1 & 24 & 0.31 & 0.20 & 0.29 & 1.00 & & & & \\
\hline$\triangle C C$ & 0.37 & 0.92 & 0 & 31 & 0.09 & 0.16 & 0.08 & 0.12 & 1.00 & & & \\
\hline$\Delta R C$ & 0.27 & 0.74 & -1 & 19 & 0.26 & 0.17 & 0.32 & 0.29 & 0.11 & 1.00 & & \\
\hline Quality & 0.43 & 0.95 & 0 & 11 & 0.09 & 0.15 & 0.09 & 0.12 & 0.34 & 0.11 & 1.00 & \\
\hline Quantity & 2.92 & 1.96 & 0 & 20 & 0.04 & 0.07 & 0.04 & 0.05 & 0.16 & 0.05 & 0.49 & 1.00 \\
\hline \multicolumn{13}{|c|}{ High Participation Level (Panel 2: 182 users; 3,822 observations) } \\
\hline Variable & Mean & S.D. & Min & Max & 1 & 2 & 3 & 4 & 5 & 6 & 7 & 8 \\
\hline
\end{tabular}

\footnotetext{
${ }^{2}$ For example, a user will earn 1 point if the user replies to a discussion question and 5 points and 10 points if the answer is marked as helpful and correct, respectively. Users can also earn points through other community activities such as posting a status update and creating an idea, among others.
} 


\begin{tabular}{|l|l|l|l|l|l|l|l|l|l|l|l|l|}
\hline SC & 1.95 & 6.80 & 0 & 185 & 1.00 & & & & & & & \\
\hline CC & 5.78 & 7.66 & 0 & 165 & 0.13 & 1.00 & & & & & & \\
\hline RC & 1.36 & 4.06 & 0 & 115 & 0.55 & 0.14 & 1.00 & & & & & \\
\hline$\Delta S C$ & 0.95 & 5.11 & 0 & 197 & 0.55 & 0.07 & 0.49 & 1.00 & & & & \\
\hline$\Delta C C$ & 0.20 & 1.22 & 0 & 13 & 0.04 & 0.11 & 0.02 & 0.05 & 1.00 & & & \\
\hline$\Delta R C$ & 0.33 & 5.22 & 0 & 53 & 0.42 & 0.09 & 0.46 & 0.36 & 0.01 & 1.00 & & \\
\hline Quality & 1.22 & 2.66 & 0 & 36 & 0.07 & 0.15 & 0.10 & 0.10 & 0.30 & 0.05 & 1.00 & \\
\hline Quantity & 3.82 & 3.67 & 0 & 51 & 0.06 & 0.13 & 0.08 & 0.09 & 0.25 & 0.05 & 0.67 & 1.00 \\
\hline
\end{tabular}

Table 1. Descriptive Statistics and Correlations Matrix

\subsection{Causality Tests with VAR Estimation}

Tables 2 and 3 report the results of causality tests using 2-lag structure for Panel 1 and Panel 2, respectively. Comparing the results between the two tables, we see different patterns of causality. For users with low and medium participation levels (Panel 1), the results show that overall, there is a twoway relationship between social capital and knowledge contribution. Not only does social capital, including structural, cognitive and relational, have a positive impact on users' knowledge contribution in terms of quality and quantity, but there is a reverse causal dependence between social capital and knowledge contribution: users with higher levels of knowledge contribution are more likely to build up their social capital (structural, cognitive and relational) in the community. In contrast, the results based on users with high participation level (Panel 2) overall show the absence of a two-way relationship between social capital and knowledge contribution. Further, the results only illustrate a one-way relationship between cognitive capital and knowledge contribution and between knowledge contribution and the change of structural capital. We will discuss and explain these findings in detail in the discussion section.

\begin{tabular}{|c|c|c|c|c|c|c|}
\hline Panel 1 & Lags & $\Delta \mathrm{SC}$ & $\Delta \mathrm{CC}$ & $\Delta \mathrm{RC}$ & Quality & Quantity \\
\hline \multirow[t]{2}{*}{$\mathrm{SC}$} & L1 & --- & --- & --- & $\begin{array}{l}0.0179^{* * *} \\
(0.0015)\end{array}$ & $\begin{array}{l}0.0177^{* * *} \\
(0.0038)\end{array}$ \\
\hline & L2 & --- & --- & --- & $\begin{array}{l}0.0024 \\
(0.0014)\end{array}$ & $\begin{array}{l}0.0071 \\
(0.0038)\end{array}$ \\
\hline \multirow[t]{2}{*}{$\mathrm{CC}$} & L1 & --- & ---- & --- & $\begin{array}{l}0.0047^{* * *} \\
(0.0005)\end{array}$ & $\begin{array}{l}0.0056^{* * *} \\
(0.0012)\end{array}$ \\
\hline & L2 & --- & --- & --- & $\begin{array}{l}0.0014^{* *} \\
(0.0005)\end{array}$ & $\begin{array}{l}0.0020 \\
(0.0012)\end{array}$ \\
\hline \multirow[t]{2}{*}{$\overline{\mathrm{RC}}$} & L1 & ---- & ---- & --- & $\begin{array}{l}0.0170^{* * *} \\
(0.0020)\end{array}$ & $\begin{array}{l}0.0169^{* * *} \\
(0.0049)\end{array}$ \\
\hline & L2 & --- & --- & --- & $\begin{array}{l}0.0064^{* * *} \\
(0.0020)\end{array}$ & $\begin{array}{l}0.0116^{*} \\
(0.0048)\end{array}$ \\
\hline \multirow[t]{2}{*}{ Quality } & L1 & $\begin{array}{l}0.0309^{* * *} \\
(0.0043)\end{array}$ & $\begin{array}{l}0.0933^{* * *} \\
(0.0036)\end{array}$ & $\begin{array}{l}0.0238^{* * *} \\
(0.0035)\end{array}$ & --- & --- \\
\hline & L2 & $\begin{array}{l}0.0168^{* *} \\
(0.0051)\end{array}$ & $\begin{array}{l}0.0472^{* * *} \\
(0.0031)\end{array}$ & $\begin{array}{l}0.0180^{* * *} \\
(0.0030)\end{array}$ & --- & --- \\
\hline \multirow[t]{2}{*}{ Quantity } & L1 & $\begin{array}{l}0.0073^{* * *} \\
(0.0021)\end{array}$ & $\begin{array}{l}0.0156^{* * *} \\
(0.0015)\end{array}$ & $\begin{array}{l}0.0043^{* * *} \\
(0.0015)\end{array}$ & --- & --- \\
\hline & L2 & $\begin{array}{l}0.0036 \\
(0.0022)\end{array}$ & $\begin{array}{l}0.0104^{* * *} \\
(0.0015)\end{array}$ & $\begin{array}{l}0.0036^{*} \\
(0.0015)\end{array}$ & $\begin{array}{l}-- \\
\end{array}$ & $\begin{array}{l}--- \\
\end{array}$ \\
\hline
\end{tabular}

Table 2. Results of Causality Tests (Low and Medium Participation Levels; 3,33o users)

\begin{tabular}{|c|c|c|c|c|c|c|}
\hline Panel 2 & Lags & $\Delta \mathrm{SC}$ & $\Delta \mathrm{CC}$ & $\Delta \mathrm{RC}$ & Quality & Quantity \\
\hline \multirow[t]{2}{*}{$\mathrm{SC}$} & $\mathrm{L} 1$ & --- & --- & --- & $\begin{array}{l}0.0077 \\
(0.0056)\end{array}$ & $\begin{array}{l}0.0122 \\
(0.0083)\end{array}$ \\
\hline & L2 & --- & --- & --- & $\begin{array}{l}0.0051 \\
(0.0056)\end{array}$ & $\begin{array}{l}-0.0019 \\
(0.0083)\end{array}$ \\
\hline \multirow[t]{2}{*}{$\mathrm{CC}$} & L1 & --- & --- & --- & $\begin{array}{l}0.0133^{* *} \\
(0.0041)\end{array}$ & $\begin{array}{l}0.0127^{*} \\
\text { (0.006o) }\end{array}$ \\
\hline & L2 & --- & --- & --- & $\begin{array}{l}0.0082 \\
(0.0043)\end{array}$ & $\begin{array}{l}0.0109 \\
(0.0062)\end{array}$ \\
\hline
\end{tabular}




\begin{tabular}{|l|l|l|l|l|l|c|}
\hline RC & L1 & \multicolumn{1}{|c|}{---} & --- & --- & $\begin{array}{l}0.0057 \\
(0.0081)\end{array}$ & $\begin{array}{l}0.0157 \\
(0.0119)\end{array}$ \\
\cline { 2 - 7 } & L2 & ---- & --- & --- & $\begin{array}{l}-0.0051 \\
(0.0090)\end{array}$ & $\begin{array}{l}-0.0102 \\
(0.0133)\end{array}$ \\
\hline Quality & L1 & $\begin{array}{l}0.1093^{* * *} \\
(0.0126)\end{array}$ & $\begin{array}{l}0.0105 \\
(0.0068)\end{array}$ & $\begin{array}{l}0.0554 \\
(0.0329)\end{array}$ & --- & --- \\
\cline { 2 - 7 } & L2 & $\begin{array}{l}0.031^{* * *} \\
(0.0127)\end{array}$ & $\begin{array}{l}0.0022 \\
(0.0054)\end{array}$ & $\begin{array}{l}0.0651 \\
(0.0426)\end{array}$ & --- & --- \\
\hline Quantity & L1 & $\begin{array}{l}0.0562^{* * * *} \\
(0.0097)\end{array}$ & $\begin{array}{l}0.0043 \\
(0.0046)\end{array}$ & $\begin{array}{l}0.0281 \\
(0.0239)\end{array}$ & --- & --- \\
\cline { 2 - 7 } & L2 & $\begin{array}{l}0.0231^{*} \\
(0.0099)\end{array}$ & $\begin{array}{l}0.0038 \\
(0.0038)\end{array}$ & $\begin{array}{l}0.0218 \\
(0.0298)\end{array}$ & --- & --- \\
\hline
\end{tabular}

Table 3. Results of Causality Tests (High Participation Level; 182 users)

\section{Discussion}

In this study, we are interested in examining the interactions between users' social capital and their knowledge contribution in the OUC context. Further, we investigate the causal relationships based on users with different levels of participation. For users with low and medium participation levels, our results (see Table 2) indicate that a two-way relationship exists between their knowledge contribution and social capital. However, the causal relationships, either between social capital and knowledge contribution or between knowledge contribution and the change of social capital, are not strictly persistent. Our explanation to this finding is twofold. First, we suggest that the effect of social capital on knowledge contribution is nonlinear. This is because when users' social capital increases, they may not be as motivated to contribute more compared to the time when they only possessed a small amount of social capital. For example, an additional 5 incoming ties (i.e., structural capital) should matter more for a user who has no ties than for a user who has 100 ties already. In other words, the marginal effect of more social capital on knowledge contribution should be decreasing in the long run. The results (see Table 3) of users with high participation level (i.e., those who have possessed extensive social capital) also echo with this explanation showing that the effects of structural, cognitive and relational capital on knowledge contribution are largely insignificant.

Second, we suggest that community growth and the resulting community size may have an impact on the relationship between knowledge contribution and social capital change. A large community provides more interaction opportunities, but individual interactions are more likely to remain unnoticed by other members (Wang et al. 2013; Wasko et al. 2004). These may impact the emergence, form and loss of social capital within a community (Wasko and Faraj 2005; Lin 2001). On the other hand, it may be difficult for members to continue to grow their social ties and expertise in a community that grows slowly, regardless of their knowledge contribution (Butler 2001; Hsiao and Chiou 2012). Unfortunately, in the present study we were not able to examine the influence of community growth and size on the causal relationships. Future studies applying comparative analysis based on multi-community data of community growth and size would be valuable to deepen and extend our understanding on the interactions between social capital and knowledge contribution.

Regarding users with high participation level, our results indicate that overall, there are no causal relationships between social capital and knowledge contribution. Nevertheless, several findings are worth discussing. First, the results (upper right in Table 3) show that for this group of users, social capital overall does not influence knowledge contribution. This finding may be explained by the concept of lead users in the OUC research. We suggest that users with high participation level are largely lead users who possess great expertise and community experience and often exhibit different personality traits (e.g., locus of control and innovativeness) than non-lead users (e.g., those in Panel 1). Studies have shown that users with a high degree of lead user characteristics tend to enjoy revealing their knowledge to other users, and their motivation for participation and contribution to the community are largely related to a wish to be recognized by the host firm and peers (Jeppesen and Laursen 2009; Jeppesen and Frederiksen 2006; Mahr and Lievens 2012). Combined, we suggest that social capital (structural, cognitive and relational) should cause knowledge contribution only for non-lead users.

Second, the effects of knowledge contribution on the change of cognitive and relational capital are insignificant (bottom left in Table 3). We measured the change of cognitive capital of a user by calculating the number of correct and/or helpful answers contributed by others that the focal user may learn from. We suggest that compared to peers, experts and experienced users may be overall more likely 
to contribute helpful and correct answers when they participate in a discussion. This could lead to no cognitive capital changes even though they have contributed in multiple discussions, based on the measure. Likewise, we measured the change of relational capital by calculating the connections where the focal user and other users followed each other. Such a measure could be problematic where the experienced users did not choose to follow back when they received ties after the knowledge contribution. Given these limitations in variable measurement, future research employing subjective measures via user self-report or survey is needed to confirm and complement our findings.

\section{Conclusion}

The objective of this study was to investigate the interplay between social capital and knowledge contribution in OUC. While previous research has overall shown that users' social capital is a good predictor of their knowledge contribution, this study shows that the relationship between social capital and knowledge contribution is far more complex than just a one-way causal relationship. We find that a two-way relationship exists between social capital and knowledge contribution among users with low and medium participation levels. For users with high participation level, our study shows that their knowledge contribution is not caused primarily by the social capital they possess in the community, while a one-way causal effect of knowledge contribution on the change of structural capital is found. In sum, our study demonstrates evidence of significant bi-directional relationships between social capital and knowledge contribution and examines the conditions (various participation levels) under which the causal relationships will exist.

With these findings, our study also provides practitioners a valuable guideline for the design of OUC. Host firms could integrate the reputation systems with social networking features in the community. Our study demonstrates that implementing social network/media features in the reputation systems will further motivate contribution by visualizing users' social capital in the community. The following/followers feature used by BMC, for instance, not only helps visualize users' social ties and connections and thereby their positions in the network but allows users to know their mutual friends and who knows whom. As a result, users are more likely to be motivated to participate in the community as they recognize the changes in their structural and relational capital. Additionally, the bookmark and notification features allow users to simultaneously derive information and knowledge without logging into the community, facilitating the cognitive capital benefits. Managers and community designers should therefore strategically adopt and implement new features and tools that will enhance social exchange and connectedness within the communities.

\section{References}

Baltagi, B.H. 2001. Econometric Analysis of Panel Data. Second Edition, Hoboken, NJ. Wiley, Inc.

Benbya, H. 2016. Successful OSS Project Design and Implementation: Requirements, Tools, Social Designs and Reward Structures, Routledge.

Borgatti, S.P. 2005. "Centrality and Network Flow," Social Networks (27:1), pp 55-71.

Borgatti, S.P., and Cross, R. 2003. "A Relational View of Information Seeking and Learning in Social Networks," Management Science (49:4), pp 432-45.

Burt, R.S. 2004. "Structural Holes and Good ideas," American Journal of Sociology (110:2), pp 34999.

Butler, B.S. 2001. "Membership Size, Communication Activity, and Sustainability: A Resource-Based Model of Online Social Structures," Information Systems Research (12:4), pp 346-62.

Cavanaugh, J.E. and Neath, A.A. 1999. "Generalizing the Derivation of the Schwarz Information Criterion," Communications in Statistics - Theory and Methods (28:1), pp 49-66.

Coleman, J.S. 1988. "Social Capital in the Creation of Human Capital," American Journal of Sociology 94, pp 95-120.

Dahlander, L., and Frederiksen, L. 2012. "The Core and Cosmopolitans: A Relational View of Innovation in User Communities," Organization Science (23:4), pp 988-1007.

Dholakia, U.M., Bagozzi, R.P., and Pearo, L.K. 2004. "A Social Influence Model of Consumer Participation in Network-and Small-Group-Based Virtual Communities," International Journal of Research in Marketing (21:3), pp 241-63. 
Faraj, S., Jarvenpaa, S. and Majchrzak, A. 2011. "Knowledge Collaboration in Online Communities," Organization Science (22:5), pp 1224-39.

Faraj, S., Kudaravalli, S., and Wasko, M. 2015. "Leading Collaboration in Online Communities," MIS Quarterly (39:2), pp 393-412.

Granger, C.W. 1969. "Investigating Causal Relations by Econometric Models and Cross-Spectral Methods," Econometrica (37:3), pp 424-38.

Greene, W.H. 2011. Econometric Analysis. Los Angeles: Pearson Education, Inc.

Heshmati, A. and Lööf, H. 2008. "Investment and Performance of Firms: Correlation or Causality?", Corporate Ownership \& Control (6:2), pp 268-82.

Hsiao, C.C., and Chiou, J.S. 2012. "The Impact of Online Community Position on Online Game Continuance Intention: Do Game Knowledge and Community Size Matter?" Information \& Management (49:6), pp 292-300.

Huysman, M., and Wulf, V. 2006. "IT to Support Knowledge Sharing in Communities: Towards a Social Capital Analysis," Journal of Information Technology (21:1), pp 40-51.

Jeppesen, L.B., and Frederiksen, L. 2006. "Why Do Users Contribute to Firm-Hosted User Communities? The Case of Computer-Controlled Music Instruments," Organization Science (17:1), pp 45-63.

Jeppesen, L.B., and Laursen, K. 2009. "The Role of Lead Users in Knowledge Sharing," Research Policy, (38:10), pp 1582-89.

Johnson, S.L., Jarvenpaa, S., Benbya, H, Barrett, M. and Faraj, S. 2017."Leadership and Online Communities," International Conference on Information Systems Proceedings.

Johnson, S.L., Safadi, H., and Faraj, S. 2015. "The Emergence of Online Community Leadership," Information Systems Research (26:1), pp 165-87.

Lin, N. 2001. Social Capital: A Theory of Social Structure and Action. Cambridge University Press.

Mahr, D., and Lievens, A. 2012. "Virtual Lead User Communities: Drivers of Knowledge Creation for Innovation," Research Policy (41:1), pp 167-77.

Nahapiet, J., and Ghoshal, S. 1998. "Social Capital, Intellectual Capital, and the Organizational Advantage," Academy of Management Review (23:2), pp 242-66.

Nambisan, S., and Baron, R.A. 2010. "Different Roles, Different Strokes: Organizing Virtual Customer Environments to Promote Two Types of Customer Contributions," Organization Science (21:2), pp 554-72.

Nov, O., Ye, C. and Kumar N. 2012. " A Social Capital Perspective on Meta-Knowledge Contribution and Social Computing," Decision Support Systems (53:1), pp 118-26.

Perry-Smith, J.E. and Shalley, C.E. 2003. "The Social Side of Creativity: A Static and Dynamic Social Network Perspective," Academy of Management Review (28:1), pp 89-106.

Phang, C.W., Kankanhalli, A., and Sabherwal, R. 2009. "Usability and Sociability in Online Communities: A Comparative Study of Knowledge Seeking and Contribution," Journal of the Association for Information Systems (10:10), pp 721-47.

Porter, C.E., and Donthu, N. 2008. "Cultivating Trust and Harvesting Value in Virtual Communities," Management Science (54:1), pp 113-28.

Robert, L.P., Dennis, A.R. and Ahuja M.K. 2008 "Social Capital and Knowledge Integration in Digitally Enabled Teams," Information Systems Research (19:3), pp 314-34.

Wang, X., Butler, B.S., and Ren, Y. 2013. "The Impact of Membership Overlap on Growth: An Ecological Competition View of Online Groups," Organization Science (24:2), pp 414-31.

Wasko, M.M., and Faraj, S. 2005. "Why Should I Share? Examining Social Capital and Knowledge Contribution in Electronic Networks of Practice," MIS Quarterly (29:1), pp 35-57.

Wasko, M.M., Faraj, S., and Teigland, R. 2004. "Collective Action and Knowledge Contribution in Electronic Networks of Practice," Journal of the Association for Information Systems (5:11), pp 721-47. 
Whelan, E. 2007. "Exploring Knowledge Exchange in Electronic Networks of Practice," Journal of Information Technology (22), pp 5-12.

Yan, J.K., Leidner, D and Benbya, H. 2018. "The Differential Innovativeness Outcomes of User and Employee Participation in an Online User Innovation Community," Journal of Management Information Systems (35:3), pp 1-34.

\section{Appendix}

\begin{tabular}{|l|l|l|l|l|l|l|l|l|l|l|l|l|}
\hline Lag & $\begin{array}{l}\text { SC- } \\
\text { Quality }\end{array}$ & $\begin{array}{l}\text { CC- } \\
\text { Quality }\end{array}$ & $\begin{array}{l}\text { RC- } \\
\text { Quality }\end{array}$ & $\begin{array}{l}\text { SC- } \\
\text { Quantity }\end{array}$ & $\begin{array}{l}\text { CC- } \\
\text { Quantity }\end{array}$ & $\begin{array}{l}\text { RC- } \\
\text { Quantity }\end{array}$ & $\begin{array}{l}\text { Quality } \\
-\Delta \text { SC }\end{array}$ & $\begin{array}{l}\text { Quality } \\
-\Delta \text { CC }\end{array}$ & $\begin{array}{l}\text { Quality } \\
-\Delta \text { RC }\end{array}$ & $\begin{array}{l}\text { Quantity } \\
-\Delta \text { SC }\end{array}$ & $\begin{array}{l}\text { Quantity } \\
-\Delta \text { CC }\end{array}$ & $\begin{array}{l}\text { Quantity } \\
-\Delta \text { RC }\end{array}$ \\
\hline 0 & 5.46 & 7.10 & 4.91 & 7.90 & 9.54 & 7.34 & 4.49 & 3.07 & 3.86 & 6.93 & 5.52 & 6.29 \\
\hline 1 & 5.40 & 7.03 & 4.85 & 7.85 & 9.47 & 7.30 & 4.42 & 3.03 & 3.83 & 6.86 & 5.50 & 6.27 \\
\hline 2 & 5.40 & 7.03 & 4.84 & 7.84 & 9.48 & 7.29 & $4.41^{*}$ & $2.95^{*}$ & $3.82^{*}$ & $6.85^{*}$ & $4.49^{*}$ & $6.26^{*}$ \\
\hline 3 & 5.39 & 7.02 & 4.85 & 7.85 & 9.47 & 7.30 & 4.42 & 2.96 & 3.83 & 6.87 & 5.50 & 6.27 \\
\hline 4 & 5.38 & 7.01 & 4.84 & 7.83 & 9.47 & 7.30 & 4.42 & 2.96 & 3.83 & 6.87 & 5.51 & 6.28 \\
\hline 5 & 5.37 & 7.00 & 4.84 & 7.83 & 9.46 & 7.29 & 4.42 & 2.97 & 3.84 & 6.88 & 5.52 & 6.29 \\
\hline 6 & 5.31 & 6.98 & 4.79 & 7.76 & 9.44 & 7.25 & 4.43 & 2.97 & 3.84 & 6.89 & 5.52 & 6.29 \\
\hline 7 & $3.98^{*}$ & $4.68^{*}$ & $3.38^{*}$ & $6.44^{*}$ & $7.45^{*}$ & $5.83^{*}$ & 4.43 & 2.98 & 3.83 & 6.88 & 5.53 & 6.29 \\
\hline 8 & 3.99 & 4.69 & 3.39 & 6.45 & 7.46 & 5.84 & 4.43 & 2.99 & 3.84 & 6.89 & 5.54 & 6.29 \\
\hline 9 & 3.99 & 4.69 & 3.39 & 6.45 & 7.46 & 5.85 & 4.44 & 3.00 & 3.85 & 6.90 & 5.55 & 6.30 \\
\hline 10 & 4.00 & 4.70 & 3.4 & 6.46 & 7.47 & 5.86 & 4.45 & 3.00 & 3.86 & 6.90 & 5.56 & 6.31 \\
\hline 11 & 4.01 & 4.71 & 3.41 & 6.47 & 7.48 & 5.86 & 4.45 & 3.01 & 3.86 & 6.91 & 5.56 & 6.32 \\
\hline 12 & 4.02 & 4.72 & 3.42 & 6.48 & 7.49 & 5.87 & 4.45 & 3.02 & 3.87 & 6.91 & 5.57 & 6.32 \\
\hline 13 & 4.03 & 4.72 & 3.42 & 6.48 & 7.49 & 5.88 & 4.46 & 3.03 & 3.87 & 6.92 & 5.58 & 6.33 \\
\hline 14 & 4.03 & 4.73 & 3.43 & 6.49 & 7.50 & 5.89 & 4.46 & 3.03 & 3.88 & 6.92 & 5.59 & 6.34 \\
\hline 15 & 4.04 & 4.74 & 3.44 & 6.50 & 7.51 & 5.90 & 4.47 & 3.04 & 3.88 & 6.93 & 5.59 & 6.35 \\
\hline 16 & 4.05 & 4.75 & 3.44 & 6.51 & 7.52 & 5.91 & 4.47 & 3.05 & 3.89 & 6.94 & 5.60 & 6.36 \\
\hline 17 & 4.06 & 4.76 & 3.45 & 6.52 & 7.53 & 5.91 & 4.48 & 3.06 & 3.90 & 6.95 & 5.61 & 6.36 \\
\hline 18 & 4.07 & 4.77 & 3.46 & 6.53 & 7.54 & 5.92 & 4.49 & 3.07 & 3.90 & 6.96 & 5.62 & 6.36 \\
\hline 19 & 4.07 & 4.77 & 3.47 & 6.54 & 7.54 & 5.93 & 4.50 & 3.07 & 3.91 & 6.96 & 5.64 & 6.37 \\
\hline 20 & 4.08 & 4.77 & 3.47 & 6.56 & 7.55 & 5.93 & 4.50 & 3.09 & 3.91 & 6.98 & 5.65 & 6.38 \\
\hline
\end{tabular}

Table 1. Lag Order Selection Using SIC (Panel 1: 3,330 users)

\begin{tabular}{|l|l|l|l|l|l|l|l|l|l|l|l|l|}
\hline Lag & $\begin{array}{l}\text { SC- } \\
\text { Quality }\end{array}$ & $\begin{array}{l}\text { CC- } \\
\text { Quality }\end{array}$ & $\begin{array}{l}\text { RC- } \\
\text { Quality }\end{array}$ & $\begin{array}{l}\text { SC- } \\
\text { Quantity }\end{array}$ & $\begin{array}{l}\text { lC- } \\
\text { Quantity }\end{array}$ & $\begin{array}{l}\text { RC- } \\
\text { Quantity }\end{array}$ & $\begin{array}{l}\text { Quality } \\
-\Delta \text { SC }\end{array}$ & $\begin{array}{l}\text { Quality } \\
-\Delta \text { CC }\end{array}$ & $\begin{array}{l}\text { Quality } \\
-\Delta \text { RC }\end{array}$ & $\begin{array}{l}\text { Quantity } \\
-\Delta \text { SC }\end{array}$ & $\begin{array}{l}\text { Quantity } \\
-\Delta \text { CC }\end{array}$ & $\begin{array}{l}\text { Quantity } \\
-\Delta \text { RC }\end{array}$ \\
\hline O & 10.91 & 9.14 & 6.87 & 12.34 & 10.60 & 8.31 & 11.03 & 4.75 & 5.88 & 12.46 & 9.68 & 7.32 \\
\hline 1 & 10.72 & 9.13 & 6.68 & 12.24 & 10.62 & 8.14 & $7.45^{*}$ & $4.73^{*}$ & $5.67^{*}$ & $8.92^{*}$ & $6.20^{*}$ & $7.12^{*}$ \\
\hline 2 & 10.81 & 9.24 & 6.76 & 12.33 & 10.73 & 8.23 & 7.56 & 4.84 & 5.76 & 9.00 & 6.22 & 7.22 \\
\hline 3 & 10.06 & 9.29 & 6.83 & 11.60 & 10.82 & 8.33 & 7.61 & 4.91 & 5.78 & 9.06 & 6.33 & 7.30 \\
\hline 4 & 10.16 & 9.24 & 6.86 & 11.71 & 10.79 & 8.35 & 7.70 & 5.02 & 5.80 & 9.12 & 6.43 & 7.36 \\
\hline 5 & 10.24 & 9.19 & 6.93 & 11.80 & 10.73 & 8.43 & 7.73 & 5.07 & 5.87 & 9.20 & 6.53 & 7.45 \\
\hline 6 & 9.16 & 9.22 & 7.00 & 10.74 & 10.80 & 8.51 & 7.75 & 5.15 & 5.94 & 9.26 & 6.59 & 7.55 \\
\hline 7 & 6.55 & $6.94^{*}$ & 5.92 & $7.96^{*}$ & $8.52^{*}$ & $7.41^{*}$ & 7.83 & 5.22 & 6.01 & 9.24 & 6.68 & 7.55 \\
\hline 8 & $6.53^{*}$ & 6.99 & $5.91^{*}$ & 7.98 & 8.62 & 7.49 & 7.82 & 5.20 & 6.02 & 9.32 & 6.69 & 7.62 \\
\hline 9 & 6.63 & 7.09 & 5.97 & 8.05 & 8.72 & 7.55 & 7.92 & 5.30 & 6.11 & 9.42 & 6.74 & 7.66 \\
\hline 10 & 6.64 & 7.08 & 5.96 & 8.16 & 8.82 & 7.60 & 7.94 & 5.30 & 6.17 & 9.50 & 6.85 & 7.76 \\
\hline 11 & 6.60 & 7.10 & 6.00 & 8.17 & 8.92 & 7.69 & 7.97 & 5.32 & 6.20 & 9.60 & 6.95 & 7.86 \\
\hline 12 & 6.58 & 7.19 & 6.00 & 8.16 & 9.01 & 7.70 & 8.04 & 5.42 & 6.29 & 9.67 & 7.04 & 7.95 \\
\hline 13 & 6.61 & 7.17 & 6.00 & 8.22 & 9.09 & 7.72 & 8.10 & 5.47 & 6.36 & 9.76 & 7.13 & 8.05 \\
\hline 14 & 6.70 & 7.26 & 6.09 & 8.33 & 9.20 & 7.81 & 8.20 & 5.57 & 6.45 & 9.87 & 7.23 & 8.12 \\
\hline 15 & 6.76 & 7.34 & 6.14 & 8.43 & 9.31 & 7.90 & 8.24 & 5.62 & 6.54 & 9.92 & 7.33 & 8.22 \\
\hline 16 & 6.81 & 7.45 & 6.25 & 8.47 & 9.41 & 8.00 & 7.99 & 5.73 & 6.61 & 9.77 & 7.42 & 8.30 \\
\hline 17 & 6.89 & 7.49 & 6.28 & 8.52 & 9.44 & 8.08 & 8.07 & 5.83 & 6.67 & 9.86 & 7.50 & 8.36 \\
\hline 18 & 6.99 & 7.57 & 6.35 & 8.62 & 9.54 & 8.18 & 8.15 & 5.94 & 6.75 & 9.96 & 7.58 & 8.47 \\
\hline 19 & 7.07 & 7.67 & 6.44 & 8.68 & 9.64 & 8.28 & 8.22 & 6.03 & 6.79 & 10.06 & 7.69 & 8.51 \\
\hline 20 & 7.12 & 7.75 & 6.51 & 8.78 & 9.71 & 8.37 & 8.24 & 6.13 & 6.90 & 10.12 & 7.88 & 8.59 \\
\hline
\end{tabular}

* indicates lag order selected by the criterion

Table 2. Lag Order Selection Using SIC (Panel 2: 182 users) 